\title{
THE ANALYSIS OF THE 35 MM ARTILLERY PROJECTILE'S MOTION MODEL PARAMETERS' IDENTIFICATION BASED ON THE RECORDED FLIGHT TRAJECTORY
}

\author{
L. Baranowski* , B. Gadomski**, P. Majewski ${ }^{* * *}$, J. Szymonik ${ }^{\dagger}$
}

\begin{abstract}
This paper describes shortly the process of identification of the mathematical model of spin stabilized artillery projectile's motion in the atmosphere. The aerodynamic characteristics needed for the motion model are identified by using artificially generated trajectory of projectile that imitates the flight path recorded by the $3 D$ Doppler radar. The trajectories of $35 \mathrm{~mm} T P-T$ projectile were generated using the motion model with 6 degrees of freedom (6DoF model) with the aerodynamic coefficients produced by PRODAS software. The identification process was conducted for the explicit form of the modified point-mass trajectory model. The main goal of the presented work is to obtain valid tool for aerodynamic coefficients identification based on real data (e.g. recorded trajectory, meteorological data) gathered during field tests. It is essential to determine the number of measurements made by radar during the projectile's flight that is necessary for the identification process to be conducted correctly. Authors present some of the results of the simulation tests - identified coefficients and errors (relative and absolute) between the original trajectories and the trajectories generated with the identified model.
\end{abstract}

Keywords: identification, exterior ballistics, projectile's motion, curve fitting, single trajectory

\section{Introduction}

According to NATO standardization documents (STANAG 4119, 2007), in order to prepare firing tables for spin stabilized artillery projectile, the knowledge of the mathematical model describing the projectile's motion as well as the meteorological conditions during its flight are needed (Cech et al., 2014). There are three most widely used projectile's motion models: point-mass (Motyl et al., 2017), modified point-mass (Baranowski, 2013) and the rigid body (STANAG 4355, 2009). The main problem is determination of the particular projectile's aerodynamic coefficients used in each model. There are several different approaches to the process of the aerodynamic coefficients identification. These methods use informations that come from tests conducted in the aerodynamic tunnels (Champigny et al., 2002), data contained in the firing tables (Baranowski and Kojdecki, 2007) or measurements of projectile's flight parameters during field tests (Chen et al., 1998 and Dutta et al., 2008). The most precise and reliable results are possible to achieve with data based on the trajectories registered during the tests on the proving grounds. This paper presents a method for the mathematical model identification process, for the $35 \mathrm{~mm}$ TP-T projectile (Baranowski et al., 2016), based on the flight parameters measured with the use of 3D Doppler radar. In the simulation tests the explicit form of the modified point-mass trajectory model (with four degrees of freedom) is used (Baranowski et al., 2016). The designed method will be used as a basic component of the software, whose main task will be generation of firing tables for anti-aircraft artillery.

Assiociate Professor Leszek Baranowski, : Department of Mechatronics, Faculty of Mechatronics and Aerospace, Military University of Technology, ul. gen. Witolda Urbanowicza 2; 00-908 Warszawa 46; PL, leszek.baranowski@wat.edu.pl

** Błażej Gadomski, R\&D Analyst: PIT-RADWAR S.A.; Poligonowa 30; 04-051 Warszawa; PL, blazej.gadomski@pitradwar.com

*** Przemysław Majewski, R\&D Analyst: PIT-RADWAR S.A.; Poligonowa 30; 04-051 Warszawa; PL, przemyslaw.majewski@pitradwar.com

† Jacek Szymonik, R\&D Analyst: PIT-RADWAR S.A.; Poligonowa 30; 04-051 Warszawa; PL, jacek.szymonik@ pitradwar.com 


\section{The procedure of the aerodynamic coefficients identification based on the recorded trajectory of projectile}

The identification process is presented in Figure 1. The identification procedure verification will be conducted for $35 \mathrm{~mm}$ TP-T ammunition, for which aerodynamic coefficients were generated using PRODAS software. Such approach ensures that the coefficients to be identified are known beforehand. The trajectories generated using those coefficients and the $6 \mathrm{DoF}$ model of the projectile's motion (Baranowski, 2013) will be treated as trajectories measured with 3D Doppler radar (noise was added to the generated trajectories).

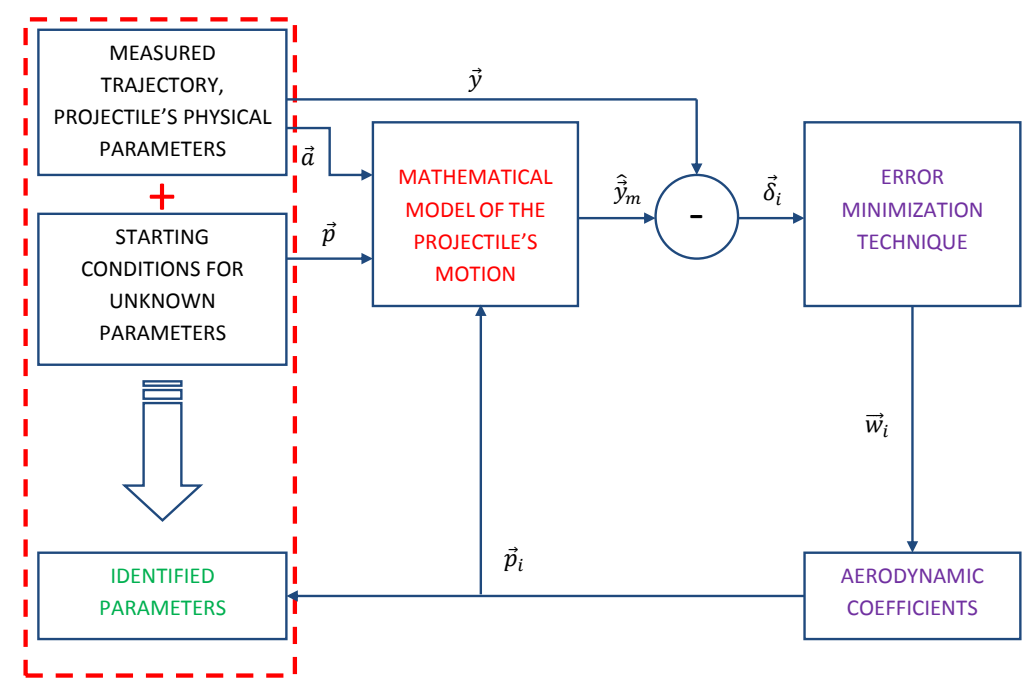

Fig. 1. Aerodynamic coefficients identification algorithm; $\vec{y}$ - array of vectors containing measurements of one trajectory i.e. projectile's position in consecutive moments in time; $\hat{\vec{y}}_{i}$ - array of vectors containing projectile's positions in consecutive moments in time generated with the use of 6DoF motion model; $\vec{a}-$ physical parameters of the projectile (muzzle velocity, mass, diameter, axial moment of inertia); $\vec{p}_{i}-$ vector containing coefficients for approximating functions that are to be identified; $\vec{p}$-vector containing starting values of coefficients for approximating functions

\section{Aerodynamic coefficients approximation}

In order to generate trajectories of projectiles, one needs physical parameters such as: initial (muzzle) velocity, mass, diameter, moment of inertia, initial rotational speed of the projectile, and aerodynamic characteristics of the projectile. As it was mentioned before, trajectories used for data identification were generated using the $6 \mathrm{DoF}$ model and aerodynamic coefficients produced by PRODAS software. The identification process was conducted with the explicit form of the modified point-mass trajectory model. The coefficients of aerodynamic forces and moments for the $6 \mathrm{DoF}$ model were interpolated using griddedInterpolant class from MATLAB environment (pchip - shape-preserving piecewise cubic interpolation). In the modified point-mass model, the coefficients of the drag force, lift force, spin dumping moment are approximated using the following functions (Shanks and Walton, 1957 and Baranowski et al., 2016):

$$
\begin{gathered}
C(\mathrm{Ma})=(1+s) A(r)+(1-s) B(r), \\
A(r)=a_{0}+a_{1} r+a_{2} r^{2}, \quad B(r)=b_{0}+b_{1} r+b_{2} r^{2}, \\
r=\left(\mathrm{Ma}^{2}-K\right) /\left(\mathrm{Ma}^{2}+K\right), \quad s=\frac{\left(\mathrm{Ma}^{2}-K\right) /\left(\mathrm{Ma}^{2}+K\right)}{\sqrt{\left(1-L^{2}\right) r^{2}}+L^{2}} .
\end{gathered}
$$

The coefficients of the induced drag and Magnus force were treated as constant values in the whole considered velocity range (such assumption does not have a significant influence on the identification process). 

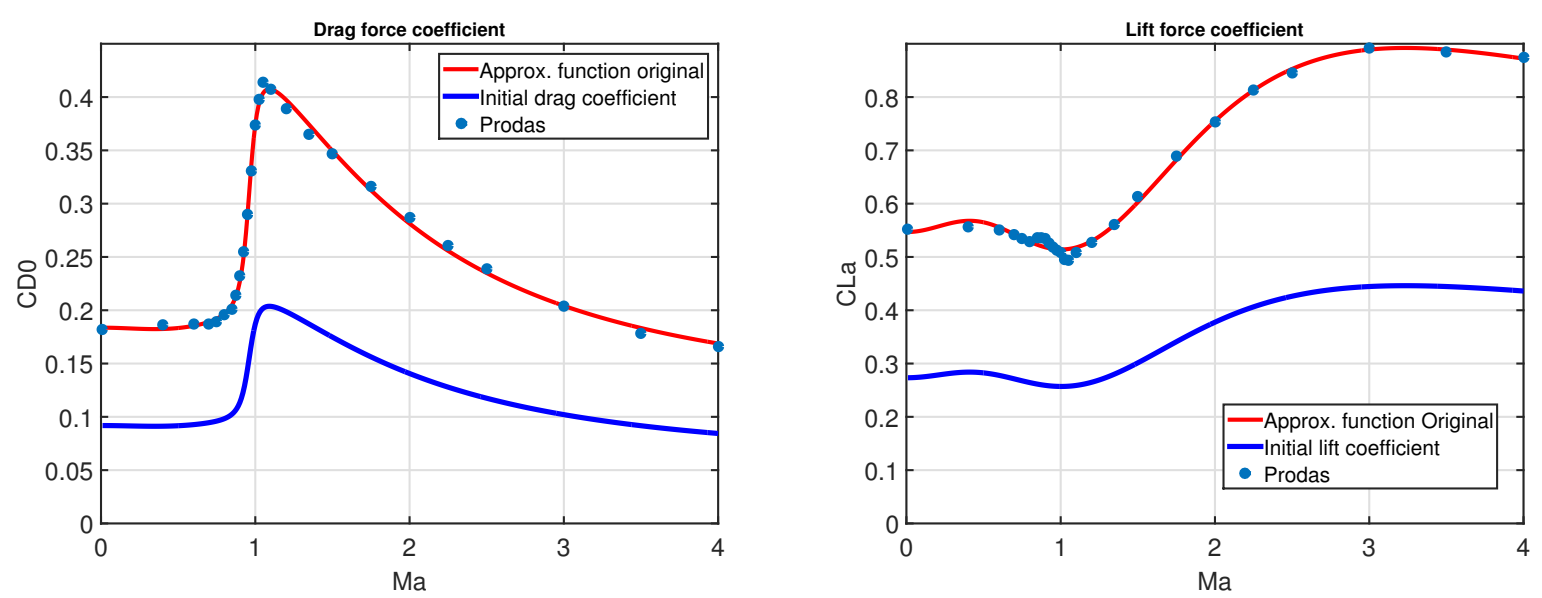

Fig. 2. Drag force coefficient (left) and lift force coefficient (right) values: original data from PRODAS (blue dots), approximating functions (original values - red line, starting values for identification process blue line).

Figure 2 shows the original and starting values of the drag and lift force coefficients. One can argue that the initial shape of the coefficient is similar to the original and, therefore, the identification process is somehow enhanced by such a choice. However, the shape of the curves describing aerodynamic coefficients as a function of Mach number for particular type of the projectile can be easily found (a good example is the PRODAS software database). Therefore, similarities in the shape of the curve are considered normal. The starting values for all the coefficients in the identification process differ from original data by at least $50 \%$.

\section{Results and conclusions}

The results of identification process of the aerodynamic drag and lift force are shown in Figure 3. Figure 4 presents the relative and absolute errors (differences between chosen parameters of original trajectories generated withe the 6 DoF model without any noise and the identified explicit form of the modified pointmass model) for projectile's range, height, drift, and velocity. The identification process was conducted for
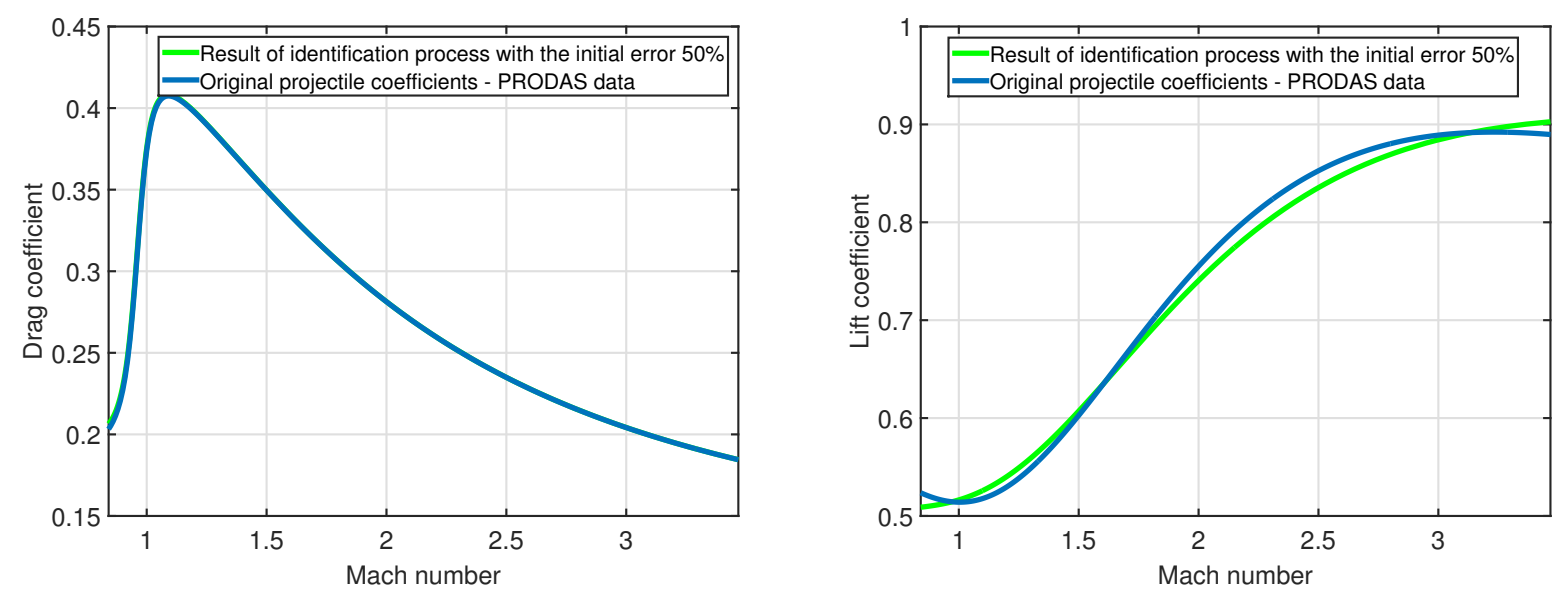

Fig. 3. Original aerodynamic coefficients generated by PRODAS and the result of identification process for drag force (left) and lift force (right).

the range of $5 \mathrm{~km}$ which is the effective range for the TP-T ammunition according to firing tables supplied by the manufacturer. It can be seen that the absolute errors for the range, drift and height are not higher than few centimeters. The discrepancies that occurred are caused by the different level of complexity of the $6 \mathrm{DoF}$ model and the modified point-mass model. The $6 \mathrm{DoF}$ model takes into account greater number of aerodynamic forces and moments that affect the projectile during flight in the atmosphere. The following conclusions can be drawn from the simulation tests: 

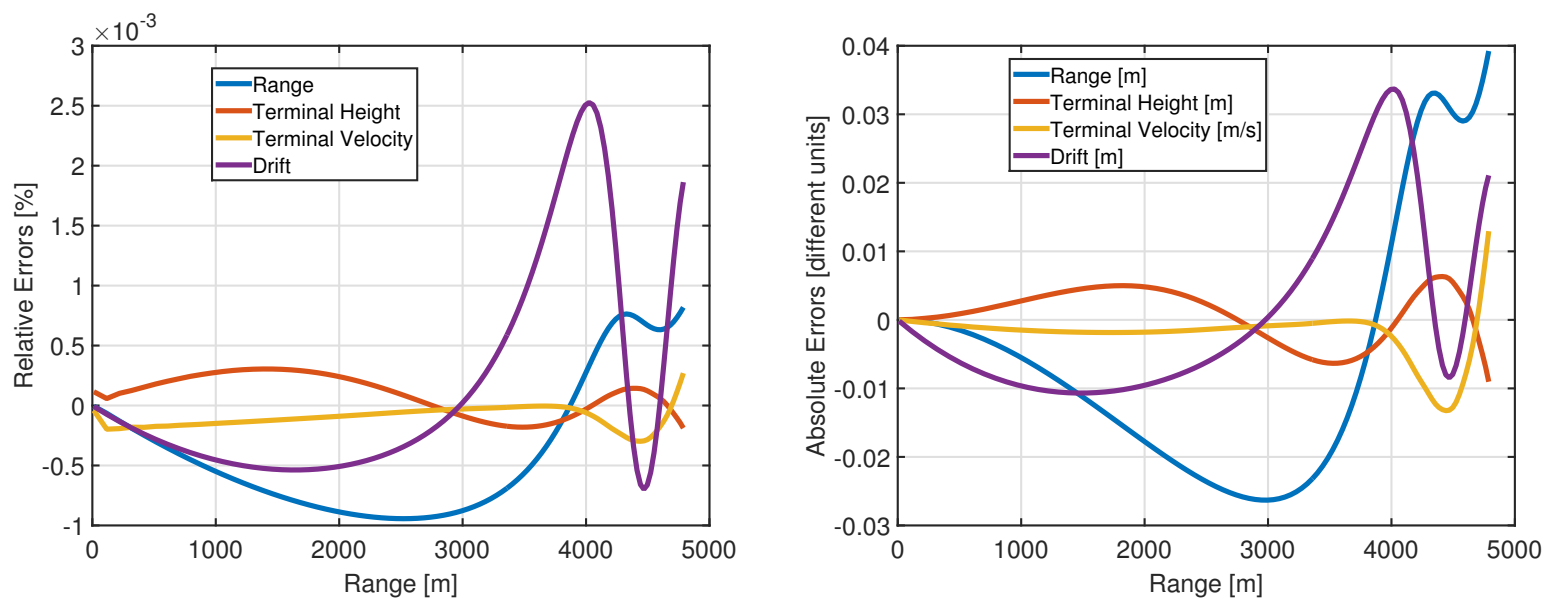

Fig. 4. Relative errors (left) and absoluter errors (right) for projectile's range, height, velocity and drift that are obtained as a result of the identification process.

- the identification process with the use of the explicit form of thee modified point-mass model was conducted correctly using the trajectory generated by the $6 \mathrm{DoF}$ model;

- the minimum number of measurement points along the trajectory of projectile (at least 50, which gives, considering the projectile flight time, one measurement for each $200 \mathrm{~ms}$ ) needed for the correct identification process was established (for the $5 \mathrm{~km}$ range the number is easily reachable by modern Doppler radars).

\section{References}

Baranowski, L. (2013) Effect of the mathematical model and integration step on the accuracy of the results of computation of artillery projectile flight parameters. Bull. Pol. Ac.: Tech., 61, 2, pp. 475-484.

Baranowski, L. (2013) Feasibility analysis of the modified point mass trajectory model for the need of ground artillery fire control systems. Journal of Theoretical and Applied Mechanics, Vol. 51, no. 3, pp. 511-522.

Baranowski, L., Gadomski, B., Majewski, P. and Szymonik, J. (2016) Explicit "ballistic m-model": a refinement of the implicit "modified point mass trajectory model". Bull. Pol. Ac.: Tech., 64, 1, pp. 81-89.

Baranowski, L., Gadomski, B., Majewski, P. and Szymonik, J. (2016) Comparison of explicit and implicit forms of the modified point mass trajectory model. Journal of Theoretical and Applied Mechanics, Vol. 54, No. 4, pp. $1183-1195$.

Baranowski, L. and Kojdecki, M.A. (2007) Inverse problem of external ballistics and algorithm for determining parameters of artillery projectile motion models. Bulletin of the Military University of Technology, Vol. 56, No. 4 (in Polish).

Cech, V., Jedlicka, L. and Jevicky, J. (2014) Some Problems with the Estimation of Projectile Trajectory Perturbations. Engineering Mechanics 2014, Brno University of Technology, Brno, pp. $116-119$.

Champigny, P., Ceroni, D., Thepot, R., Cayzac, R., Carette, E., Trouillot, C. and Donneaud, O. (2002) Recent developments on aeroballistics of yawing and spinning projectiles: part I - wind tunnel tests. In Proceedings of 20th International Symposium on Ballistics, pp. 203-208.

Chen, Y., Wen, C., Gong, Z. and Sun, M. (1998) High-order iterative identification of projectile's aerodynamic drag coefficient curve from radar measured velocity data. IEEE Transactions on Control Systems Technology, Vol. 6, No. 4, pp. 563-570.

Dutta, G., Singhal, A., Kushari, A. and Ghosh, A.K. (2008) Estimation of drag coefficient from radar tracked flight data of a cargo shell. Defence Science Journal, Vol. 58, No. 3, pp. 377-389.

Motyl, K., Magier, M., Borkowski, J. and Zygmunt, B. (2017) Theoretical and experimental research of anti-tank kinetic penetrator ballistics. Bull. Pol. Ac.: Tech., 65, 3, pp. 399-404.

Shanks, D. and Walton, T.S. (1957) A New General Formula for Representing the Drag on a Missile Over the Entire Range of Mach Number. NAVORD Report 3634.

STANAG 4119, (2007) Adoption of a standard cannon artillery firing table format, North Atlantic Treaty Organization.

STANAG 4355, (2009) The Modified Point Mass and Five Degrees of Freedom Trajectory Models, Edition 3, North Atlantic Treaty Organization. 